\title{
As actividades desportivas no Porto de 1900
}

\author{
José V. Ferreira \\ Faculdade de Ciências do Desporto e de Educação Física \\ Universidade do Porto, Porto, Portugal
}

\author{
António. G. Ferreira \\ Faculdade de Psicologia e de Ciências da Educação \\ Universidade de Coimbra, Coimbra, Portugal
}

\section{https://doi.org/10.5628/rpcd.01.02.56}

\section{RESUMO}

Num livro publicado na década de quarenta, criticava-se os portuenses desse tempo por se considerarem desportistas quando só cuidavam de assistir aos jogos do seu clube e a discutir sobre o futebol. Alegava o seu autor que no Porto de 1900 se praticava a natação, o jogo do pau, a esgrima, a equitação, a ginástica, o remo, o ciclismo, a tauromaquia, o levantamento de peso e halteres e que a juventude não descuidava as práticas físicas, nem desconhecia a competição desportiva.

No sentido de verificarmos a qualidade da referida opinião, pretendemos neste artigo dar conta das actividades físicas e desportivas mais relevantes para o Porto no início do último século do segundo milénio, bem como descortinar qual o relevo que estas então assumiam para a sociedade da segunda maior cidade do país, a partir do impacto que elas tiveram em dois jornais aí publicados.

Palavras-chave: Desportos, modalidades, Porto, jornais, 1900.

\section{ABSTRACT}

The sporting practices in the city of Porto in the year 1900

A book published in the 1940's criticised the people of Porto because they considered themselves as sports people when all they did was watch their own team's games and argue about football. Its author alleged that, in Porto in 1900, people took part in swimming, "jogo do pau", fencing, equestrian events, gymnastics, rowing, cycling, bullfighting and weightlifting, and that young people were neither disinterested in physical activity nor in competitive sport.

In order to establish the quality of the abovementioned opinion, we intend, with this article, to highlight the range of sports activities in Porto, at the beginning of the last century. We also intend to reveal the social importance of these activities in the country' s second largest city, based on the impact they had on two newspapers published at that time.

Key Words: Sports and activities, Porto, newspapers, 1900. 
Num livro publicado na já longínqua década de quarenta, Arnaldo Leite, querendo criticar os conterrâneos do seu tempo por se considerarem desportistas quando só cuidavam de assistir aos jogos do seu clube e a discutir futebol, afirmava que, afinal, não havia razão para se pensar que a sociedade de então devotava mais cuidado à prática das actividades desportivas que a da transição do século XIX para o XX. Alegava o referido autor que já no Porto de 1900 se verificava a prática da natação, da esgrima, da ginástica, do jogo do pau, do remo, do ciclismo, do levantamento de pesos e halteres, etc. e que a juventude desse tempo não descuidava as práticas físicas, nem desconhecia a competição desportiva (2).

O texto no entanto merece uma atitude crítica. Ele reflecte uma opinião de alguém censurador da atitude passiva que as pessoas já então apresentavam relativamente ao fenómeno desportivo e, principalmente, ao excessivo apego devotado aos assuntos do futebol. De facto, Arnaldo Leite não se mostrava muito entusiasta desta modalidade. Explicava ele claramente a sua posição, temendo apodarem-no de antidesportista: "Eu não detesto todas as bolas e até simpatizo com a bola com "b", pequeno: - bola do tênis, bola do pingue-pongue, bola do hóquei, bola do bilhar, etc., etc... A minha embirração é com a outra, a tal, a marmanjona, que tantos estragos causa. Essa é que eu não engulo. Talvez por ser grande demais..." (2, p. 57).

O futebol era já um desporto arrastador de multidões e, por isso, quase monopolizava as atenções das pessoas, impedindo-as de se dedicarem a outros desportos ou actividades. Na opinião de Arnaldo Leite, a bola estava para o desporto, como o fado para a rádio e a revista para o teatro; a tendência para baixo era bem evidente nisto tudo (2). Ora o referido autor, remando contra a maré, pretendia defender que tal situação não representava nenhum progresso relativamente ao ambiente lúdico-desportivo vivido no início do século. Para ele, o balanço era bem evidente:

"Em 1900 - Sem bola: Educação Física. Desportistas amadores. Desenvolvimento da raça.

Em 1949 - Com bola: Zero a zero. Desportistas profissionais. Desenvolvimento da "massa" (2, p. 52).
Esta posição de Arnaldo Leite tem o seu interesse porquanto, resultando da sua experiência, apresenta um valor testemunhal. Todavia, a sua postura crítica exigiu que procurássemos confirmar, numa outra fonte, elementos mais elucidativos sobre o impacto das actividades desportivas, na sociedade portuense, durante o ano de 1900.

A escolha recaiu nos jornais diários que, então, se publicavam no Porto e, para isso, procurámo-los na Biblioteca Pública Municipal desta cidade.

Infelizmente, o estado dos referidos diários complicou a nossa tarefa. O Jornal de Notícias estava demasiado deteriorado e, por conseguinte, não foi possível consultá-lo; o Comércio do Porto e o Primeiro de Janeiro também não estavam em bom estado e acessíveis aos leitores, mas, depois de alguns contactos com uma funcionária superior, encontrámos uma solução para o problema: utilizámos o Comércio do Porto para o primeiro semestre e o Primeiro de Janeiro para o segundo. Os dois jornais tinham bastante em comum. Para além de serem ambos editados na cidade do Porto, saíam os dois nos mesmos dias da semana, não se publicando, porém, à segunda-feira, eram diários generalistas, possuíam o mesmo número de páginas (4) e as colunas tinham a mesma largura $(5,5 \mathrm{~cm})$. Entre os aspectos a distingui-los, estava o seu tamanho: o Comércio do Porto media $77 \mathrm{~cm}$ de altura e 44 de largura e o Primeiro de Janeiro tinha as dimensões de $64,5 \mathrm{~cm}$ de altura e 44 de largura. Em ambos os jornais, a primeira página acolhia os artigos mais importantes, entre os quais se destacava a política portuguesa e as notícias sobre o estrangeiro. Por vezes, entre outras referências, lá aparecia uma ou outra sobre algo relacionado com actividades físicas e desportivas. A terceira e a quarta páginas destinavamse quase exclusivamente à publicidade $\mathrm{Na}$ pesquisa efectuada nos mencionados jornais, optámos por recolher todas as referências relacionadas com actividades físicas e desportivas, quer relatassem competições, demonstrações e práticas físicas, quer dissessem respeito a anúncios de provas, de espectáculos e de materiais desportivos ou mesmo a notícias de reuniões de clubes e de associações desportivas.

O resultado da recolha efectuada pode traduzir-se, sintética e globalmente, no quadro 1 : 
Quadro 1 - Número de referências sobre as várias modalidades físico-desportivas, no ano de 1900.

\begin{tabular}{|c|c|c|c|c|c|c|c|c|c|c|c|c|c|}
\hline Actividades & Jan & $\mathrm{Fev}$ & Mar & Abr & Mai & Jun & Jul & Agt & Set & Out & Nov & Dez & Total \\
\hline Atletismo & & & 2 & & & & & & & & & & 2 \\
\hline Caça & & 3 & 5 & & & & 2 & 10 & 2 & 4 & 1 & & 27 \\
\hline Canoagem & & & & & & & & 5 & 4 & & & & 9 \\
\hline Ciclismo & & & 3 & $1+5^{*}$ & $3^{*}$ & $17+3^{*}$ & 8 & 13 & 20 & 4 & 3 & & 80 \\
\hline Equitação & & & & & & & & 1 & 5 & & & & 6 \\
\hline Esgrima & & 5 & & 2 & & & & & & & & & 7 \\
\hline Ginástica & 16 & 37 & 3 & 4 & & 1 & & 1 & 3 & 10 & 7 & 2 & 84 \\
\hline J.Tradicionais & & & & & & & & 2 & 8 & & & & 10 \\
\hline Luta & & & & 1 & & & & & & & & & 1 \\
\hline Natação & & & & & & & & 3 & 1 & & & & 4 \\
\hline Passeios Fluviais & & & & & 1 & & 4 & 2 & & & & & 7 \\
\hline Patinagem & 3 & 4 & 6 & 4 & & & & & & & & & 17 \\
\hline Ténis & & & & & & & & & & 1 & 1 & & 2 \\
\hline Tiro & & & & & 4 & 8 & 3 & 6 & 1 & 1 & 2 & 1 & 26 \\
\hline Touradas & & & & & & 1 & 13 & 46 & 33 & 20 & & & 113 \\
\hline Total & 19 & 49 & 19 & 11 & 5 & 10 & 30 & 89 & 77 & 40 & 14 & 3 & 395 \\
\hline
\end{tabular}

* Cicloturismo

Como podemos verificar no quadro 1, o panorama desportivo de 1900 era muito diferente do actual e até do de 1949, ano em que foi escrito o texto de Arnaldo Leite que referimos. Em menos de um século ou mesmo de meio, Portugal viu surgir e desenvolver-se um considerável número de modalidades, o que alterou por completo o quadro desportivo português. Não admira que alguns, como o fazia Arnaldo Leite, se sentissem pouco adaptados a tal transformação e reagissem tecendo críticas que, normalmente, assentavam sobre a modalidade despertadora de maior interesse. De facto, devia-lhes parecer preocupante a pujança do futebol, quando em 1900 se podia percorrer as páginas de um jornal diário sem se encontrar uma única referência à sua prática.

Olhando bem para o quadro 1, vê-se, no entanto, que não é só o futebol a estar ausente dos jornais compulsados. Nenhum dos desportos mais praticados actualmente aparecem aludidos. Aliás, não encontrámos notícias de qualquer desporto de bola, a não ser que consideremos o registo do ténis num anúncio de venda de um palacete a possuir um campo para a prática deste jogo (5).

Gráfico 1 - Histograma sobre o número de referências no tocante às diversas actividades desportivas, no ano de 1900.

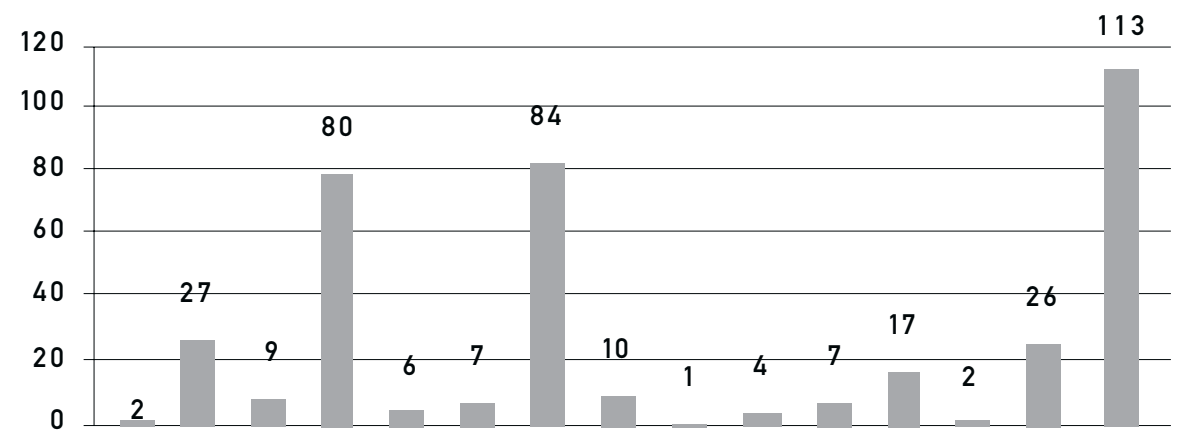


Analisando o gráfico 1, podemos ver que as actividades contempladas com maior número de referências nos jornais foram as corridas de touros, o ciclismo, a caça e o tiro; por seu turno, a luta, o atletismo, o ténis e a natação foram pouquíssimas vezes mencionadas.

Por certo, hoje em dia, estranhar-se-á que consideremos as corridas de touros no âmbito da análise das práticas físicas e desportivas. No entanto, elas gozavam de imensa popularidade em todo o país, sendo algo surpreendente que encontrássemos tantas referências relativas a povoações situadas a norte do rio Mondego. Parece-nos que as touradas estavam para as populações do início do século, como o futebol para as de hoje. Será que o futebol veio ocupar o espaço outrora pertencente à tauromaquia? Ao observarmos o quadro 1 e o gráfico 1 , apreciaremos certamente a posição relativa da ginástica, mas convém explicitar que um número tão alto de referências advém de elas contemplarem do mesmo modo a ginástica acrobática praticada nos circos. De facto, se excluíssemos as notícias relativas aos circos, nem uma dúzia de referências obteríamos para a ginástica. Todavia, é preciso ter-se em conta que não era tão nítida como actualmente a diferenciação entre a ginástica artística e alguns exercícios atléticos praticados nos circos.

Perspectivando a análise a partir de critérios actuais, é o ciclismo que merece maior atenção dos jornais. No entanto, também aqui temos diversos tipos de práticas: competições velocipédicas, corridas onde se privilegiava sobretudo o aspecto lúdico e o cicloturismo.

Estas duas últimas práticas eram organizadas pelo Real Velo Clube do Porto e nelas podiam participar homens e mulheres. No Palácio de Cristal realizavam-se, por exemplo, corridas de fitas para um e outro sexo e, com a participação de homens e mulheres, desenvolveram-se vários passeios a cidades como a Aveiro e Braga (4 e 5).

Quanto às competições de bicicleta, o grande promotor delas era o mesmo Velo Clube, mas igualmente se empenhavam nesta tarefa algumas casas vendedoras de velocípedes como a Ferreira Real e a Garagem Lusitana (4 e 5).

No sentido de ficarmos a perceber o nível desta modalidade no virar do século, vejamos o quadro de competições organizadas pelo Real Velo Clube do Porto no velódromo Maria Amélia, em 1900, para comemorar o sétimo aniversário do seu nascimento:

Quadro 2 - Provas de ciclismo promovidas pelo Velo Clube, em 1900, nos festejos comemorativos do seu $7^{\circ}$ aniversário.

\begin{tabular}{lccclc} 
Prova & Séries $\left(\mathrm{n}^{\circ}\right)$ & $\begin{array}{c}\text { Distância metros } \\
\text { (série/final) }\end{array}$ & $\begin{array}{c}\text { Corredores } \\
\text { (total) }\end{array}$ & $\begin{array}{c}\text { Vencedor } \\
\text { Prémio } \\
\text { (réis) }\end{array}$ \\
\hline Resistência Profissional & 2 & $900 / 3600$ & 9 & José Bento Pessoa & 20.000 \\
Handicap & 1 & 1800 & 4 & Tomás da Silva Castro & $\begin{array}{c}\text { Objecto arte } \\
\text { Nacional Amadores }\end{array}$ \\
Nacional Profissional & 1 & $900 / 1500$ & 10 & L. Lacerda Pinto & Relógio \\
& 1 & 1800 & 9 & António Lopes & 11.000
\end{tabular}

Numa apreciação genérica, facilmente verificamos que as corridas se destinavam a amadores e a profissionais, tanto mais que a prova denominada de "handicap" era especialmente reservada aos sócios amadores do Real Velo Clube do Porto. Olhando, tanto a globalidade do evento desportivo como cada uma das provas em particular, vemos que o número dos corredores participantes era escasso o que parece traduzir ainda um incipiente desenvolvimento da modalidade. Devemos esclarecer que os ciclistas profissionais a participarem na prova "Nacional" foram os mesmos a competirem na de "Resistência". No entanto, entre estes nove corredores encontrámos profissionais originários de Lisboa, Viseu, Figueira da Foz, Aveiro, Braga e Porto o que parece demonstrar já uma implantação da modalidade a nível nacional.

Curiosamente, a patinagem, embora se tratasse de uma modalidade bem diferente do ciclismo, aparecia associada sobretudo a iniciativas do Velo Clube do Porto. As actividades registadas aconteciam nos meses de Inverno, ou seja, de Janeiro a Abril, 
período em que não se organizavam competições de ciclismo. Corridas de patins, corridas de fitas e de obstáculos em patins para ambos os sexos eram competições muito queridas dos sócios do Velo Clube, as quais se realizavam todas as semanas, normalmente, nas noites de quinta-feira e sábado, no Palácio de Cristal, em recinto fechado (4 e 5). Juntamente com a patinagem, a caça e o tiro perfazem um trio de modalidades que registavam um número de referências entre as quinze e as trinta, ou seja, posicionavam-se como um grupo intermédio, não conhecendo a popularidade das touradas ou do ciclismo, mas merecendo muito mais atenção que muitas outras. Note-se que a caça registou vinte e sete referências e o tiro vinte e seis, número superior ao da patinagem e bem longe do obtido pelos jogos tradicionais a alcançarem apenas a dezena. A caça tinha o seu maior número de notícias no Verão e, através delas, procurava-se dar a conhecer os locais repovoados de caça, bem como disciplinar a arte venatória. O tiro, por sua vez, era uma actividade de Primavera e Verão e, durante este tempo, o Clube de Caçadores do Porto organizava, no terreno de Salgueiros, dois tipos de torneios: tiro a chumbo e à bala (4 e 5).

Para além destas, as outras modalidades quase não tinham expressão. De entre elas, o remo/canoagem era a actividade desportiva mais noticiada, seguindose os passeios fluviais, a esgrima e a equitação (4 e 5). Para aquilatarmos a qualidade das competições de remo/canoagem organizadas pelos Bombeiros Voluntários do Porto em 1900, atentemos no programa: $1^{\text {a }}$ corrida - Escaleres de 4 remos; $2^{\text {a }}$ corrida - Sapatas a duplo remo; $3^{\mathrm{a}}$ corrida - "Picnics"; $4^{\text {a }}$ corrida - Caíque; $5^{\mathrm{a}}$ corrida - Barcos saveiros a dois remos (5).

As referências às modalidades parecem indicar uma actividade física mais concentrada em determinadas épocas do ano, conforme podemos ver no quadro $3 \mathrm{e}$ no gráfico 2 .

Quadro 3 - Número de referências, por trimestre, no que diz respeito a algumas actividades desportivas, no ano de 1900.

\begin{tabular}{lccccc} 
Actividades & $\mathbf{1}^{\circ}$ Trimestre & $\mathbf{2}^{\circ}$ Trimestre & $3^{\circ}$ Trimestre & $4^{\circ}$ Trimestre & Total \\
\hline Caça & 8 & 0 & 14 & 5 & 27 \\
Ciclismo & 3 & 29 & 41 & 7 & 80 \\
Ginástica & 56 & 5 & 4 & 19 & 84 \\
Jogos tradicionais & 0 & 0 & 10 & 0 & 10 \\
Patinagem & 13 & 4 & 0 & 0 & 17 \\
Tiro & 0 & 12 & 10 & 4 & 26 \\
Touradas & 0 & 1 & 92 & 20 & 113 \\
Total & 80 & 51 & 171 & 55 & 357
\end{tabular}

Gráfico 2 - Histograma sobre o número de referências, por trimestre, relativo a algumas actividades desportivas, no ano de 1900

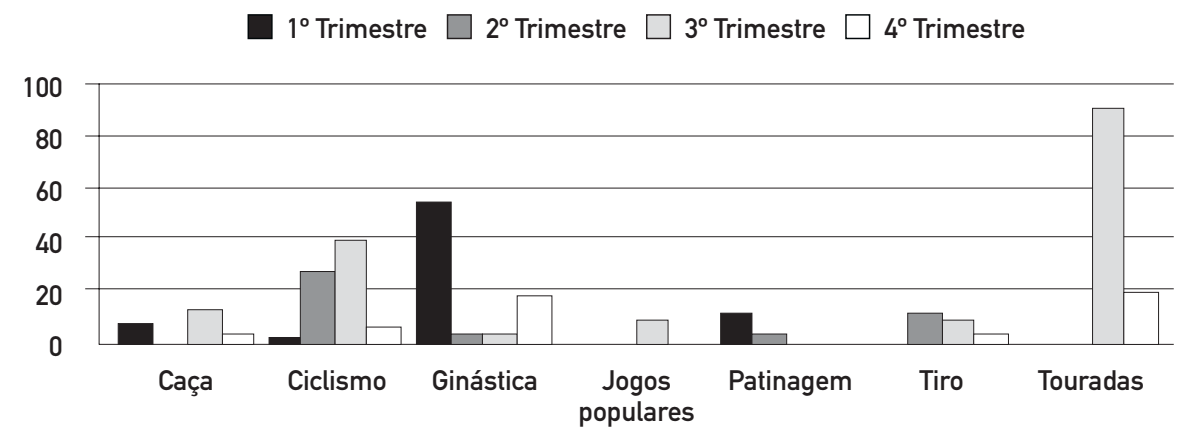


Parece evidente que é, no Verão, no $3^{\circ}$ trimestre que há maior prática das actividades físicas mencionadas, tendo-se encontrado o número de 171 referências, muito acima das 80 do $1^{\circ}$ semestre e mais ainda das 55 e 51 , respectivamente, do $4^{\circ}$ e $2^{\circ}$ semestres. Analisando com maior pormenor, vemos que o ciclismo e o tiro são modalidades praticadas preferentemente na Primavera e no Verão. Por seu turno, a ginástica é uma disciplina mais desenvolvida no Outono e especialmente no Inverno.

\section{CONCLUSÃO}

De tudo o que foi dito, se colige que, quer ao nível da variedade das modalidades, quer ao nível das referências, a prática desportiva no norte do país era bastante pobre. Excluídas as touradas e as actividades referentes ao circo, praticamente só o ciclismo tinha alguma expressão. Depois do ciclismo, unicamente a caça e o tiro pareciam ter alguma importância, tendo em conta o número de referências, uma vez que só elas ultrapassavam o número de 20.

Levando em atenção os dados colhidos nos jornais, não parece haver razão para a opinião do Arnaldo Leite. É natural que ele se tivesse referido ao conjunto das actividades praticadas pela juventude e, portanto, não devidamente organizadas. De qualquer modo, parece ser evidente que as práticas desportivas ainda não mobilizavam os jornais.

\section{BIBLIOGRAFIA}

1. Ferreira, J. V., Ferreira A. G. (1997). La gymnastique à Porto à la fin du XIX ème siècle et l'action de Paulo Lauret. In Atti del $1^{\circ}$ Seminario Europeo di Storia dello Sport. Roma, p. 180-184.

2. Gama, A. (1952). O "Porto 1900": crónicas. Porto: Livraria

Figueirinhas.

3. Hasse, M. (1993). O divertimento do corpo. Corpo, Lazer e Desporto, na transição do século XIX para o século XX, em Portugal. Tese de Doutoramento. Lisboa: UTL / FMH.

4. J. Comércio do Porto (1900). $1^{\circ}$ semestre.

5. J. Primeiro de Janeiro (1900). $2^{\circ}$ semestre.

6. Parreira, L. L. (1937). Os desportos na formação moral. Revista a saúde escolar. 18: 520-523.

7. Pontes, J. (1934). Quási um século de desporto. Lisboa: Sociedade Nacional de Tipografia.

8. Vaquinhas, I. M. (1992). O conceito de decadência

"fisiológica da raça" e o desenvolvimento do desporto em Portugal. Finais do século XIX / princípios do século XX. Revista História das Ideias. 14: 365-388.

\section{CORRESPONDÊNCIA}

\section{José Vítor Ferreira}

Faculdade de Ciências do Desporto

e de Educação Física

Universidade do Porto

Rua Plácido Costa, 91

4200.450 Porto

Portugal

[jferreira@fcdef.up.pt] 